\title{
Avaliação do Rendimento Escolar: \\ Estudos e ConcepçÃo
}

Dair Aily Franco de Camargo*

\section{RESUMO}

No presente artigo, além de lançar mão de informações da literàtura, como comumente se faz, peço licença e me autorizo a cmitir sobre avaliação escolar, minhas próprias icléias c opiniões, fruto de muitos anos de investigação, vivência em salas de aula, problemas e reflexão.

\section{I - INTRODUÇÃO}

Falar de avaliação, a meu ver, implica necessariamente em falar antes sobre os objetivos do ensino, partindo do pressuposto que o que se avalia é a medida cm que esses objetivos, colocados pelo professor, foram atingidos.

Parece já ser de consenso não só que a avaliação varia em função desses objelivos mas, que eles, por sua vez, variam também, cin função da concepção filosófica de cducação ou de "homem educado" do professor.

As feiçõcs assumidas pelo quadro alual do nosso sistema escolar nos permitem inferir que a grande maioria dos professores julga que cabe a eles c à escola "transmitir" conhecimentos e informações; caberia a eles, portanto, avaliar a memorização, a retenção dessas informações.

Mas não é por este caminho que enveredará o presente texto; acredito que, sob esta perspectiva, nada teria a acrescentar de novo àquilo que dezenas de manuais de Didática e de Avaliação já têm publicado.

Sou de opinião que outros devem ser os objetivos do ensino; conseqüentemente, que outras devem ser as formas e finalidades da avaliação.

Em artigo publicado por mim, (Camargo, 1985) apresentei um "modelo de ensino" onde, para cada uma das ctapas do trabalho do professor cm sala de aula, busquei extrair um embasamento da tcoria psicogenética de J. Piaget. A Revista da ANDE assim se pronunciou na abertura do reforido artigo:

"O artigo que publicamos apresenta um ponto de vista sobre os funclamentos tcóricos e metodológicos da Didática embasados em J. Piagel. $\wedge$ Revista da ANDE tom posição definida quanto à função da escola pública como socializadora de conhecimentos, entendendo que eles devem passar

* Proiessor Adjunto do Departamento de Educaçăo do Instituto de Biociências - UNESP - Rio Claro - SP. 
pelos crivos de seus determinantes históricos e sociais. Reconhece que os conhecimentos são objetivos, não neutros. Portanto, a ênfase nos diferentes moldes de agir e operar em relação aos conteúdos escolares não deve levar a uma sobrevalorização dos processos mentais. Conteúdos/métodos devem ser associados à perspectiva dos objetivos sócio-políticos da escola. Este trabalho atende a uma das alternativas teóricas do enfoque da Didática, na busca de caminhos metodológicos para um ensino que garanta o encontro formativo entre o aluno e os conteúdos (grifos meus) (ANDE, 5(9):43-53, 1985).

Apesar da posição bem clara assumida pela Revista da ANDE, continuo acreditando e batalhando no sentido de que o objetivo da escola e dos professores é sim, o de garantir o "encontro formativo entre o aluno e os conteúdos", pois, somente uma cabeça pensante, bem formada, terá condições de se aproveitar dos objetivos sócio-políticos da escola; somente "sobrevalorizando os processos mentais", formando mentes capazes de raciocinar, de propor, de discernir, estaremos possibilitando aos cidadãos opinar com base, com fundamento, com sentido; somente ajudando os alunos a construírem suas próprias ferramentas intelectuais, estaremos colaborando na formação de indivíduos dignos, críticos e criativos, em lugar de meros repelidores de idéias alheias. Não é da oralidade que necessitamos mas sim, da oralidade assentada na inteligência, pois a palavra vale quanto vale a inteligência de quem a pronuncia. Minha opinião é a de que a escola tom seu compromisso com a inteligência, com o conhecimento sim. Cabe a ela ensinar o aluno a pensar, trabalhar no seu desenvolvimento cognitivo, se quiser contribuir na formação de indivíduos argutos, isto é, habilitados intelectualmente para reivindicar seus direitos e cônscios de suas responsabilidades.

Concordo com todos aqueles (em especial, Kolhberg, 1972 e Furth, 1966 c 1973) que julgam que o objetivo do ensino deve ser, em última análise, o fortalecimento do pensamento, a base sobre a qual se assenta a aprendizagem de qualquer disciplina particular.

Tal objelivo sempre fez parte de minhas preocupações como docente universitária, embora que durante alguns anos, de forma implícita e mal delineada; faltava-me o embasamento teórico necessário para explicitá-lo com toda a clareza. Fazia falta o conhecimento de uma teoria explicativa convincente sobre o desenvolvimento mental, seus problemas e suas contradições. Faltava-me diferenciar, no plano teórico, entre aprendizagem e desenvolvimento, memória e inteligência, inteligência e aprendizagem, elc.

Tal referencial teórico, eu o encontrei satisfatória e plenamente desenvolvido por J. Piaget. Nesse momento remeto o leitor a leituras de algumas obras básicas para entender e refletir sobre alguns conceitos piagetianos que julgo imprescindiveis na discussão dos problemas de avaliação do rendimento escolar; entre esses conceitos, os mais fundamentais a meu ver, são: caracterização e diferenciação entre desenvolvimento e aprendizagem, entre os aspectos figurativos e operativos da cognição e entre as experiências do tipo físico e lógico-matemático na interação do sujeito com o objeto de 
conhecimento (cf.Piaget, 1974; Furth, 1973 e 1974). É com base nesse referencial teórico que dou prosseguimento às minhas idéias e concepções solse avalią̧ăo do rendimento escolat:

\section{II - AS MMINLAAS PESQUUIIAS SOBRE AVALLACCÃO}

A preocupaçăo com a avaliação me acompanha clesde que entrei pela primeira vez numa sala de aula, na qualidade de professora de Eslalíslica para alunos do $2^{\circ}$ ano do Curso de Pedagogia. Analisando agora exemplares das minhas primeiras "provas", posso constatar que meu objelivo nunca foi avaliar a memorização de conceitos e teoremas, as demonstrações, a ulilização e emprego correlos de fómulas, a exalidão numérica dos cálculos, clc. Em lugar disso, sempre solicitei deles que explicassem e exemplificassem cerlos conceitos a partir de frases transcritas dos livros, que encaminhassem corrctamente a solução de um problema (sem necessariamente desenvolvêla alé o final), que tirassem conclusões a partir de cerlas alirmações ou premissas, clc. Tentava enfim propor siluações que os fizessem reflelir, raciocinar, organizar e explicilar seus pensamentos, cle.

Os resullados, creio mesmo que seria desnecessário mencionar, eram "desastrosos". Importante é acrescentar o "comentário" dos alunos: "Mas nós só vamos mal na Estalística; nas demais disciplinas não lemos problemas de nolas".

Também creio não ser preciso gaslar muilas palavras para colocar o quanto tal comentário me deixava preocupada. Restava-me pois, na qualidade de professora recém-formada, descolorir a ravão de lais resultados.

Foi vivenciando esses problemas e constatando seus resultados que planejei minha primcira pesquisa sobre avaliação. Scu objelivo era verilicar se os "maus" alunos em Estalística o cram somente nessa disciplina. Estalisticamente, colocar tal objelivo implica em veriilicar se a "medicla de concorctância" da posição ocupada pelos alunos, nas scis (6) disciplinas (do respeclivo currículo, era significaliva ao nível de 0,05. O procedimento consistiu em apanhar na secretaria da Faculdade, as médias finais dos alunos em cada uma dessas seis (6) disciplinas e calcular a partir delas o Cocficiente de Concordância de Kendall (Siegel, 1956). O resultado oblido foi incequívoco: a posição ocupada pelos alunos dentro da classe e nas scis disciplinas cra a mesma c, lal resultado era significalivo alé o nivel de (0,0)1! (Camargo, 1977); e essa posição era a mesma, independentemente da escala de notas ulilizada pelos respectivos professores'.

Esse resultado, se por um lado trouxe-me alguma trancjüilidade, por outro, forçou-me a planejar novas pescyuisas na lentaliva de comprecender melhor mous próprios problemas na avaliação dos alunos. E posso dizer, sem

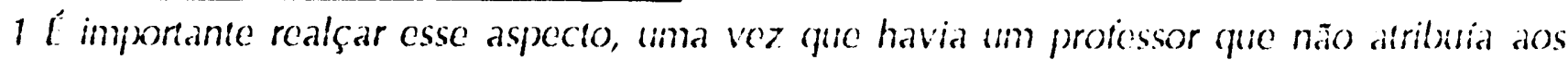
alunos notas menores que sete (7); mas, o aluno que recebia sele (7) com esse proiessor era o mesmo que recebia nota um (1) ou clois (2) cm ristatistica. 
nenhum exagero, que meus trabalhos sobre o assunto continuam até hoje e que o que apresento neste arligo sobre avaliação tem o respaldo de algumas dessas pesquisas por mim realizadas. Para facilitar essa exposição, a seqüência na apresentação dos resultados obedecerá a mesma seguida na realização das refericlas pesquisas:

1. O rendimento escolar do aluno do anligo Curso Primário, numa série, condiciona ou determina seu rendimento nas séries seguintes. Esse resultado é váliclo até para a $4^{\text {a }}$ série onde 34\% (Coeficiente de Determinação Múltipla segundo Blalock, 1960) (da variância das notas oblidas pelos alunos podem ser explicados em função de suas notas nas séries anteriores (Camargo, 1975).

2. A reprovação escolar, como prálica educacional corrente em nosso sistema de ensino, é completamente incficiente. O aluno, mesmo repetindo três vezes o conteúclo programático de uma dada série, não consegue atingir o nivel de clesempenho daquele não-reprovado (Camargo, op. cii.).

3. Também o aproveilamento do aluno do anligo Curso Ginasial, numa disciplina, é condicionado ou correlacionado com seu rendimento em lodas as demais disciplinas. Toda a matriz de correlação das notas obtidas na $4^{a}$ série ginasial é significaliva ao nível de (0,01! O valor de correlação mais alto obtido ioi entre P'ortuguês e Matemática. Isto equivale dizer que o "bom" aluno numa disciplina o é lambém em todas as outras (Camargo, 1977).

4. Se as avaliações fogem da cobrança de informações retidas e reproduzicla, então, para o profiessor, atribuir uma nota cinco (5) $\mathrm{cm}$ Didática, por exemplo, é "Ião diricil quanto" atribuir uma nota cinco (5) cm Estatística. Cheguei a essa conclusão no primeiro ano que lecionei Didática para os alunos dos cursos de Licencialura na USP' de Ribeirão Preto, em 1970.

5. Se o objelivo do professor de $3^{\circ}$ grau, na avaliação, é cobrar a aquisição de conhecimento (reprodução de hatos, princípios, iniormações, etc.), ele se torna uma "iigura dispensável" em sala de aula. Para este lipo de avaliação e referindo-se ao aluno universitário, em nacla contribui a diversificação de alividades ou de procedimentos de ensino por parte do professor (Camargo e Casagrande, 1979).

6. 1)a mancira como são realizadas as avaliações em nosso sistema de ensino, não existe nenhuma correlaşão entre desempenho escolar e desempenho operatório, ou seja, entre aprendizagem e desenvolvimento, no sentico piageliano dos tormos (Camargo, 1990).

7. Alunos do $1^{\circ}$ grau que firepüentam classes de professores que estruturam rigidamente o ambiente disciplinar e o conteúcto a ser trabalhado, sobressaem-se quando se considera o desempenho escolar; contudo se se enfocar o desempenho cognitivo ou operatório, os alunos dos "profiessores democráticos" (os que estruluram menos rigidamente) levam vantagens (Camargo, n.p.).

Analisando detidamente esses sete resultados, vemos que os mesmos podem ser suldedividides em dois grupos:

a) Aqueles que apontam para a inclicácia do sistema de reprovação como prálica corrente em nossas escolas, uma ve\% que existe dependencia 
linear significativa entre as nolas oblidas pelos alunos durante lodo o período de quinze (15) anos de sua escolaridade (resultaclos 1, 2 e 3) e

1) Aqueles que apontam a col)rança, em nosso sistema de avaliação do rendimento escolar, de aspectos especílicos, estálicos, figurativos de aprendizagem - através da memorização de informações - completamente desvinculadas das possibilidades operatórias do aluno (resultados 4, 5, 6 e 7).

Como explicar esses dois resullados gerais?

Em função do quadro tórico ulilizado, poderia levantar algumas explicações sobre:

1) O allo poder preditivo das notas nas várias disciplinas e nos cxames finais das diversas séries de escolaridade (da primeira à úllima!).

$\wedge$ escola, em seus diversos niveis, fornece ao aluno infomaçóces e cobra a sua reprodução: meras "avaliações liguralivas", bascadas cm "experiências físicas" de aprendizagem, isto se as entendermos como a apreconsĩo, pelos alunos, das propriedades e informações sobre o objelo de estude, geralmente inseridas num texto a ser lido (Camargo, 1992).

Segundo Kiminyo (apud. Chakur, 1984) a educadeão ocidental aponta para o ensino de habilidades de linguagem e regras de desempenho em exames; os alunos nas escolas lom pouco lempo para a liberdacle necessária a experiências aulo-reguladoras, para os aspectos operativos de conhecimento, ou seja, sua capacidade de transformar e aplicar os conhecimentos específicos que são cruciais ao desenvolvimento cognilivo. Eles repelem, como papagaios, explicações cientíticas sobre, por exemplo, centro de gravidade, que não compreendem e que thes são lotalmenle inadequadas. Exige-se de crianças de 6 ou 7 anos que encontrem exemplos de palavras que sejam, ao mesmo tempo, polissilabas e paroxílonas, lambém indelecpadamente.

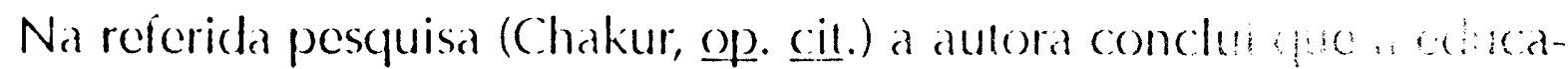

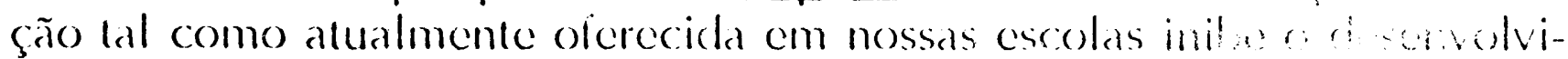
mento intelectual e, aponta entre os hatores explicativos denes inibiegaro, a ausência de alividades por parte do aluno e a ênfase na meneriedeãe dos contcúclos.

Se o objelivo da educação é criar homens capazes de hazer coisas novas e não simplesmente repelir o que as outras geracẽos fi/cram, como conseguir isso? Como lermos mais larde adultos crílicos a crialivos, se cles passaram 15 a 20 anos de suas vidas, acpucles mais cruciais ao desenvolvimento inlelectual, copiando e reputindo os "ensinamenlos" dos livros? Ninguém consegue ser crílico e criativo se munca encontrou oportunidades para sê-lo. Poucos conseguirão fazer coisas signilicativas mais tarde, se passaram quase um terço de suas vidas ouvindo o professor - o intermediário entre as palavras impressas nos livros e a menle dos alunos.

Não é de conhecimento da maioria dos educadores que sua função é ajudar o aluno em seu desenvolvimento cognitivo; (daí não "colbrarem" em suas avaliações os aspectos operalivos de conhecimento, aqueles que procedem do interior do indivíduo e que dão sentido às suas experiências: as sínte- 
ses, as relações, as interprelações, as avaliações, elc.

Nesse sentido podemos dizer que o nosso sistema de ensino é allamenle coerente e consistente. $\wedge$ escola cobra dos alunos um delerminado lipo de "habilidade" que se repele, seja na Matemálica, seja no Inglês, ou seja na I listória: a memorização de informações. O aluno que possui lal "habilidade" sair-se-á bem nas avaliações, qualquer que seja a disciplina considerada.

Oulra explicação possivel para esses dados é que as estruluras básicas da inteligência são as mesmas, independentemente dos conteúclos aos quats se aplicam: um lísice que elabora uma nova leoria sobre a origem do universo, um pocta que redige um poema ou um cosinheiro que cria uma nova reccila, estão, igualmente, fazendo uso da inlcligência.

Dianle do que foi dilo alé aqui, poderíamos encerar nossas explicações dizendo que o fato de "ir bem" na escola indica apenas que o individuo atingiu um determinado nível de competência cognitiva e de domínio da "habilidade" de memorização que the permilem assimilar o conteúdo curricular da mancira "desastrosa" como vem senclo "Irabalhado" hoje em nossas escolas.

2) ^ desvinculação, nas avaliações escolares, entre os aspectos especílicos de aprendizagem e aqueles relativos ao desenvolvimento cognitivo do aluno.

Se entendermos por aproveitamento escolar - conforme nosso quadro teórico - a construção ou elaboração de formas de pensar e raciocinar sobre os conteúdos ensinados, fica lácil concluir que isso implica num certo processo, num certo desenvolvimento.

Para um prof́essor, assumir lal concepção implica em centralizar a sua alenção nos processos de intervenção que levam à construção de formas mais claboradas de pensamento; implica em deixar de lado a idéia de cque lal construção é esponlânca, obrigatória, nalural e inevilável.

Assumindo lal postura, na avaliação nossa larefa não é mais a de quantilicar os "acertos", ou seja, o quanto o aluno já domina mas, o de discernir nas suas açoes os "crros construlivos", únicos indicadores de seus progressos menlais. E aqui reside a grande diiiculdade: não sabemos lidar construlivamente com o erro. Não conseguimos considerá-lo a não ser para "coltar", "sublrair" a nota do aluno. Tentamos a lodo custo cvila-lo, cobrande do aluno a repeliegão de frases pronlas ou de respostas já preparadas nos livros.

Noro acqui um parênleses para uma recapitulação teórica sobre o assunlo (ci. Davis e Espósilo, 1990) que, creio, traráa aos prof́essores que lêcom o presente artigo, alguma contribuição nas suas larefas de avaliação.

Numa alividade realizada pelo aluno dois aspecios estão sempre presenles: um objutivo a ser alingido e os meios ulilizados para alcançá-lo. Realizar uma larela implica pois na compreensão do problema e na busca de procedimentos para resolvê-lo. É o nível estrulural do aluno que fixará os limites dentro dos quais ele poderá assimilar a siluação problema e oferece- 
rá a gama de procedimentos possiveis para resolvê-lo. Dentro desse conjunto de soluções possíveis, determinado pelo seu desenvolvimento intelectual, caberá ao aluno escolher alguns que resolvam o problema.

As alternativas que então se colocam são:

a) O aluno acerta a solução do problema. Neste caso, caberá ao professor colocar-the novos problemas que provoquem desequilíbrios, levando-o a novas construções cognilivas. verificar:

b) O aluno erra a solução do problema. Neste caso, caberá ao professor

- O aluno é capaz de resolver o problema, apenas escolheu mal o procedimento? (Isso significa que o aluno possui as estruturas necessárias à solução do problema).

- O aluno sequer compreende o sentido do que the está sendo apresenlado? (Isso significa que o aluno não consegue assimilar o problema porque seu sistema cognitivo não está suficientemente desenvolvido para que ele o perceba como perturbador de seu equilíbrio intelectual).

- O aluno é desequilibrado pelo problema mas, não apresenta as estruturas de pensamento necessárias para solucioná-lo? (Isso signiiica que o aluno lem dificuldades tanto para compreender o problema como para selecionar a estratégia de ação, isto é, existem lacunas nas suas estruturas cognilivas que dificultam a assimilação dos dados que ele $1 \mathrm{~cm}$ à sua disposição).

Somente neste último caso podemos falar em "erros construtivos". Nessas ocasiões o aluno procederá por ensaio e erro, fazendo correções de suas estratégias em função dos exitos e fracassos na ação que ele realizou. Conseqüentemente, ele modifica neste processo, não só a sua ação mas também a forma (le conceber o problema.

Nos outros dois casos, o que ocorre é bem diverso: ou o aluno já sabe, ou sequer entende a tarefa que the está sendo proposta. No primeiro caso cabcrá ao professor propor novas larelas e, no segundo, trabalhar na construção de esquemas anteriores, pré-requisilos necessários à compreensão do problema. O professor não pode esperar resposta de um aluno que secpuer entendeu a pergunta.

Na presente ólica, a larcla do professor é tornar o erro gradalivamente observável ao aluno, para que ele se tome construtivo e assim, tornar a avaliação mais produliva.

Decorrente desta posição teórica, o crro deve ser visto pelo professor como o resultado de uma postura de experimentação onde o aluno levanta suas hipóteses, plancja suas estratégias de avaliação e as põe à prova. Com essa nova postura diante do erro, lalve\% o professor lenha condiȩões de avaliar mais adequadamente o rendimento de seus alunos. 


\section{III - CONCLUSÃo}

Diante do que acabei de expor, creio que resta-me ainda disculir dois aspecios:

1. Acé que ponto essas idéias todas interferiram no meu trabalho $\mathrm{cm}$ sala de aula? alunos?

2. Como tais "mudanças" se refletiram nos resultados apresentados pelos

O primeiro aspecto que merece destaque foi o da ampliação das oporlunidades e alividades avaliadas: aluação em grupo, elaboração de planos de atuação, trabalho prálico realizado nas escolas, elaboração de relatórios, discussões em comum, emissão e justificação de opiniões, organização e apresentação escrila sobre questões teóricas relevantes, elc.

Minhas avaliações não se restringem mais a respostas específicas fornecidas a questões lambém especílicas, respostas fechadas para pergunlas também fechadas ou limiladas (avaliações a curto prazo). Encaro minhas avaliações mais no sentido de desenvolvimento (avaliações a longo prazo); só assim aspectos como mudanças de atilude, honestidade intelectual, cooperação, etce, podem ser consideradas e devidamente avaliadas.

E quanto aos alunos?

Depois que se conhece alguns aspectos da teoria piagetiana, particularmente os três indicados no inicio deste trabalho, não se consegue mais olhar para o aluno com os mesmos olhos, nem avaliá-lo da mesma mancira. O aluno agora é outro: é um ser cognoscente que interagindo com os objelos, tenla assimilá-los às suas estruturas cognitivas, deforma-os segundo as suas limitações ou possibilidades, modifica-se diante da força do objeto, faz perguntas, coloca-se hipóleses provisórias para lentar verificá-las, acerla ou crra em suas previsões.

Não tenho nenhum dado quantilativo que comprove a superioridade dessa nova prálica de avaliação; contudo, intuitivamente percebo que o trabalho desenvolvide sob esta ólica $1 \mathrm{em}$ mais a ver $\mathrm{com}$ a realidade dos alunos, é mais significativo, contextualizado, prepara-os melhor para lidar com os problemas profissionais.

Como o desenvolvimento lambém é levado em conta e não apenas as aprendizagens especílicas, julgo necessário tempo para poder avaliar os efcilos do ensino, das centativas de desequilíbrio no desenvolvinento do aluno.

É equívoco do profiessor julgar que somente alravés de "perguntas bem difíceis", de "provas complexas", ele terá condições de realmente avaliar scus alunos. Minha experiência permite atirmar que é outro equivoco julgar que o aluno que consegue tirar "boas" notas na escola, com o tipo de questões como aqui apresentados, será mais tarde um probissional competente. Competente sera acpuele que encontrou em sua vida escolar oportunidades amplas para tentar construir, errar, tentar novamente, emitir opiniōes, julga- 
mentos, clc.

Se é na avaliação que (ransparecem os objelivos reais perseguidos pelo professor, se através dela podemos inclusive condicionar a mancira como o aluno estuda uma dada disciplina então, creio que poderemos também, alravés do oferecimento de siluações múlliplas de avaliação, "condicioná-lo" a estudar pensando: em suas alividacles profissionais fuluras, nos problemas que deverá enfrentar e tentar solucionar em sua vida diária.

\section{REFERÊNCIAS BIBLIOGRÁFICAS}

Blalock, H.N. (1960) Social Slalistics. Mc Ciraw Ilill Book Co., N.Y..

Camargo, D. Aily F. de e L.D.R. Casagrande. (1978) ^ influência cla estralégia e da avaliação ulilizadas pelo proiessor, no rendimento (los alunos. Anais da IX Reunião Anual de P'sicologia, Ribcirão P'oclo, 102-103.

Camargo, D. Aily F. de. (1985) ^ Didálica nos cursos de formação de prolessores - um enfoque piageliano. $\triangle \mathrm{ND}) \mathrm{E}$, ^no $5(9): 43-46$.

Camargo, D. Aily F. de. (1992) ^ Escola Pública de 5" a 8* sćries: algumas características dos alunos, dos professores e do trabalho docente em sala de aula. Cadernos de Educacão) Paidéia, FF(LRP-USP, Rilucirão Prelo, 2:10-28, fev./jul..

Camargo, D. Aily F. de. (1990) Desempenho operatório e desempenho escolar. Cadernos de Pesquisa, S.P. (74):47-56, ag..

Camargo, D. Aily F. de. (1975) Um eslude quanlibalivo sol)re a reprovação no curso primário. Cadernos de P'esquisa, S.P. (12):3-18, mar..

Camargo, D. Aily F. de. (1977) Um eslude (quanlitalivo solse o rendimento escolar expresso em nolas. Caclemos de Pesquisa, (21):9-14.

Chakur, C.R.S.L. (1984) Um estudo solore a defasagem no descenvolvimento cognitivo de crianças escolares e crianças trabalhadoras: a psicogênese das noções de classificação e volume. Relatório apresentado para linal de estágio probatório cm RDII)P - FF(.LRP-USP?

Davis, C. e Y.L. Esposilo. (1990) Papel e função do erro na avalia(̧ão escolar. Cadernos de Pesquisa (74):71-7.5. 
Furh, II.G. (1974) Piagel e o conhecimento: fundamentos léricos. R.)., Forense.

Furh, II.C. (1973) Piaged na sala de aula. R.J., Forense

Furth, II.C. (1966) Thinking withoul language: psychological implications of deafiness. N.Y. The Free Press.

Kohll)erg, L. e R. Mayer. (1972) Development as the aim of Education. Harvard. Rev. 42(4):449-496.

Piaget, J. (1972) Desenvolvimento e aprendizagem (in Lavatelli C.S. and F. Stendller: Readlings in child hehavior and development. 3 rd. ecl., Harcourt Brace Jovanovich lnc., N.Y., USA).

Siegel, S. (1956) Non-parametric slatistics for the behavionral sciences. N.Y. Mc: Craw I lill

\section{ABSTRACT}

This paper uses the common ways of dala collecting in literature, and also the author's own ideas, thoughts and opinions, based on many years of research, problem-solving and classroom experiences.

Palavras-chaves: avaliaşa escolar, rendimento escolar, atribuição de notas, desenvolvimento cognitivo e crros construtivos.

k'y-words:school evalution, school achievement, marks assignement, cognitive development and conseructive mistakes. 